Artigos

\title{
Retratos não-modelares da modernidade Hegemonia e contra-hegemonia no pensamento brasileiro
}

\author{
Non-standard portraits of modernity \\ Hegemony and counter-hegemony in Brazilian social thought
}

Sergio B. F. Tavolaro*

\begin{abstract}
Resumo: O presente artigo almeja apurar no seio do pensamento social brasileiro a existência de elementos que indiquem alternativas a noções sociológicas consolidadas acerca da modernidade. Indaga-se sobre as premissas que subjazem imagens do Brasil talhadas em algumas obras ditas "clássicas" de interpretação de nossa formação social. Em seguida, busca-se identificar peças-chave do quadro de referência que, desde longa data, circunscreve os horizontes de ideação sociológica acerca da experiência moderna. Logo após, são contempladas as reflexões de analistas contemporâneos a respeito do valor heurístico de retratos do país delineados no seio do pensamento brasileiro. Por fim, à luz de programas e abordagens da teoria social contemporânea, lança-se mão de insights e sugestões ensaiadas em tais interpretações "clássicas" com o propósito de indicar saídas a alguns dos impasses e limites da sociologia da modernidade sublinhados na atualidade.
\end{abstract}

Palavras-chave: Modernidade. Pensamento social brasileiro. Teoria sociológica.

\begin{abstract}
While interested in non-standard experiences of modernity this article delves into "classic" oeuvres of the so-called Brazilian social thought as it searches for alternative concepts, categories and perspectives on modern sociability. It starts with the investigation of the premises that underlie and circumscribe the works of some of the most prestigious interpreters of Brazil. It then sheds lights on key components of the hegemonic frame of reference that informs sociological accounts on modernity up to these days. Finally, in light of contemporary social theory, the article lays out some elements for a counter-hegemonic discourse of modernity.
\end{abstract}

Keywords: Modernity. Brazilian social thought. Sociological theory.

\footnotetext{
* Doutor em Sociologia pela The New School for Social Research (Nova York, EUA), professor do PPG em Sociologia da UnB em Brasília, DF, Brasil <sergiotavolaro@hotmail. com>. O presente artigo é fruto de pesquisa financiada pelo CNPq (Edital Bolsa Pesquisa de Produtividade). Agradeço as sugestões dos(as) pareceristas da Civitas, que me auxiliaram a aprimorar este trabalho.
}

Civitas, Porto Alegre, v. 17, n. 3, e115-e141, set.-dez. 2017

Exceto onde especificado diferentemente, a matéria publicada neste periódico

é licenciada sob forma de uma licença

Creative Commons Attribution-NonCommercial-NoDerivatives 4.0 International License 


\section{Interpretações do Brasil e alguns de seus horizontes de ideação}

Eis um fato notório acerca do universo intelectual brasileiro: quem quer que se ocupe das obras de alguns dos mais celebrados intérpretes do Brasil fatalmente perceberá um sentimento bastante generalizado - refirome ao desconforto de parcela significativa desse universo em relação ao estatuto propriamente moderno da sociedade brasileira. Não tardará também a constatar que essa espécie de mal-estar com bastante frequência nutre-se da percepção de que as referências cognitivas, morais, legais, comportamentais, estéticas e institucionais quase sempre associadas à ordem moderna não nos cabem da mesma maneira e/ou na mesma proporção observada em um grupo seleto de sociedades tidas por originárias e/ou vanguardistas da modernidade. Por fim, cedo notará a extensa dispersão de retratos do Brasil que se propõem desvelar as raízes, manifestações e contornos dos predicados e idiossincrasias dessa experiência, em direções tão diversas quanto sua compleição política, sua dinâmica econômica, sua organização jurídico-moral, sua vida artísticointelectual, seu universo mental, e assim por diante. Ao fim e ao cabo, a imagem que se sobressai nesses exercícios é quase invariavelmente a de uma configuração societária mal encaixada no concerto da modernidade, imagem especular distorcida de formas que não são originalmente suas, em evidente descompasso com os "centros modernos dinâmicos" - um diagnóstico, aliás, que atravessa diferentes gerações de intérpretes e se prolonga no presente. ${ }^{1}$ Tamanha a força desse juízo - alusivo a uma vida nacional sem paralelo ou, de maneira menos contundente, a um quadro societário aproximado ao de outros igualmente destoantes de configurações ditas "modelares" - que, a princípio, talvez se pudesse esperar que nossas criações mentais mais elevadas fossem vistas, elas mesmas, como produtos inéditos, criações genuínas, reflexos inconfundíveis de uma realidade única em seus traços mais essenciais ipso facto, sinal a mais daquele desacerto. Não é essa, porém, a percepção prevalecente. Na verdade, parece preponderar a opinião de que também nossas autorrepresentações e autopercepções - inclusive aquelas lavradas no seio do chamado pensamento social brasileiro - se abastecem de ideias oriundas de outros contextos, muito embora careçam do brilho e da sofisticação observados

\footnotetext{
${ }^{1}$ Tal diagnóstico repetidas vezes faz-se acompanhar de ainda outro, a saber: o pretenso "padrão imitativo" de nossas formulações intelectuais, gostos, referências institucionais, padrões comportamentais, anseios, ordenamentos legais etc. (ver Nabuco, 2000, p. 136; Romero, 1949, p.296; Cunha, 1981, p.137-138; Bomfim, 1993, p.171; Torres, 1982, p. 175; Vianna, 1987, p. 265; Prado, 2012, p. 139; Hollanda, 1936, p. 122; Faoro, 2001, p. 826-827; Ramos, 1996, p. 68; Costa Pinto, 1978, p.61-62; Fernandes, 2008a, p. 25-26; Candido, 2010, p. 11-12; Ianni, 1978, p. 186-187, dentre outros).
} 
em suas aparições “originais” (Bosi, 1995; Costa, 2010; Cruz Costa, 1964; Lynch, 2013; Schwarz, 2009a; Schwarz, 2009a; Schwarcz, 1993; Ventura, 1991).

O objetivo precípuo do artigo é apurar, no próprio caldo desse pensamento social - um universo intelectual reconhecidamente variado, disperso e heterogêneo (Botelho e Schwarcz, 2009; Cardoso, 2013; Liedke, 2005; Vianna, 2004) -, a existência de elementos e noções que eventualmente indiquem alternativas a essas convicções duradouras. ${ }^{2}$ De acordo com a primeira hipótese deste trabalho, porquanto seja inadequado referir-se a tais imagens e retratos perenes do Brasil como se fossem criações inéditas, fruto de uma realidade irredutível em seus traços mais essenciais, tampouco parece satisfatório tratá-los como decalques imperfeitos de elementos e referências estranhos a ela. De outro modo, parece-me que algumas das principais noções e ideias de que se servem esses retratos inscrevem-se em certo imaginário cujo alcance e escopo logram delimitar os horizontes de ideação (codificação, interpretação e explicação) de um amplo e variado conjunto de contextos societários. Ora, como decerto se poderia supor, esse exercício conduz-nos a indagar acerca do próprio quadro de referência sob cuja guarda e proteção a sociedade brasileira tendeu a ser apresentada, em diferentes momentos e por secções distintas daquele universo intelectual.

Conforme a segunda hipótese do trabalho, embora informados por esse quadro de referência, os retratos e imagens há pouco aludidos dispõem de elementos e noções sugestivos de olhares, percepções e abordagens alternativas da modernidade, isto é, capazes de contemplar aspectos, facetas e dimensões da experiência moderna subapreciados ou de todo desconsiderados por aquele imaginário. Ainda de acordo com essa hipótese, na maior parte dos casos, tais ensejos jamais chegam a constituir um esforço deliberado com vistas à formulação sistemática e articulada de discursos contra-hegemônicos da modernidade. De outra forma, a presença dessas sugestões é residual e difusa, imiscuída em narrativas e imagens (do Brasil bem como de outros contextos que lhe servem como parâmetro) que se amparam preferencialmente em referências cognitivas e normativas desde longa data consolidadas. Almejo debruçar-me sobre essa presença dispersa e residuária que colore o pensamento brasileiro com o propósito de destilar sugestões para narrativas sociológicas

\footnotetext{
${ }^{2}$ Não se quer de maneira alguma sugerir que não haja diferenças no interior desse universo intelectual. Tomadas em suas especificidades, várias dessas formulações são reconhecidamente irreconciliáveis. Ainda assim, a ambição do artigo é tratar de ao menos algumas das convergências de seus "retratos e imagens do Brasil" e, a partir delas, explorar seu potencial cognitivo.
} 
contra-hegemônicas. Ao menos nesse sentido específico, o presente artigo constitui um esforço de construção de teoria a partir de "retratos não-modelares da experiência moderna".

É preciso esclarecer que a eleição desse problema de reflexão não se deve à mera crença em certa qualidade especial do pensamento social no Brasil para fornecer chaves explicativas e interpretativas universais. Trata-se, na verdade, de uma agenda de pesquisa beneficiária de outra hipótese de trabalho, por sua vez avançada por um conjunto numeroso de analistas contemporâneos, pertencentes a distintas gerações, qual seja: ao invés de simples caudatárias, subsidiárias ou meras replicações (mais ou menos criativas) de formulações lançadas a partir do "centro", elaborações intelectuais situadas e projetadas desde experiências sociais "não-modelares" (dentre as quais a brasileira) mostram-se equipadas para oferecer insights à compreensão não apenas de aspectos e situações diretamente associados à (suposta) especificidade de sua posição, mas da própria condição moderna amplamente considerada. Em contiguidade a essa conjectura, importa-me avaliar em que medida "retratos não-modelares da modernidade" inscritos em algumas de nossas mais prestigiadas empresas interpretativas auxiliam-nos a diversificar e ampliar o rol de ferramentas cognitivas, pontos de vista, noções e parâmetros sociológicos passíveis de serem mobilizados em esforços de compreensão, explicação e codificação da experiência societal contemporânea.

Além deste introito, é minha intenção identificar peças-chave do quadro de referência que, desde longa data, circunscreve os horizontes de ideação sociológica acerca da experiência moderna. Logo em seguida, almejo revisitar as reflexões de analistas contemporâneos a respeito do valor heurístico de imagens e retratos do país delineados no seio do pensamento brasileiro. Por fim, à luz de programas e abordagens da teoria social contemporânea, pretendo lançar mão de insights e sugestões ensaiadas em interpretações "clássicas" de nossa formação com o propósito de indicar alternativas a impasses e limites da sociologia da modernidade sublinhados na atualidade.

Antes de iniciar, fazem-se necessárias três explanações metodológicas: primeiramente, quanto à opção por obras de interpretação do Brasil como meio de abordar as questões há pouco anunciadas, acompanho análises que se atêm a essa produção por pressentirem nelas certo potencial heurístico (Brandão, 2007, p.41-42; Bastos e Botelho, 2010, p.493; Lima, 2013). Significa dizer que, embora de modo algum pareçam-me desprezíveis os avanços metodológicos, analíticos e teóricos observados desde a profissionalização das ciências sociais no Brasil, compartilho da avaliação de que a capacidade para descortinar aspectos e facetas importantes da sociedade brasileira é 
também extensiva à "fase ensaística" desse universo intelectual (Bastos e Botelho, 2010; Cardoso, 2013; Lima, 2013, p.70-74). Em segundo lugar, longe de capricho deste autor, saliento que a atenção do presente artigo a um conjunto de trabalhos ditos "clássicos" do pensamento brasileiro resulta do reconhecimento de sua recorrência em parcela expressiva das ementas e programas de disciplinas (de graduação e pós-graduação) devotadas a essa área de investigação bem como de seu lugar de destaque e prestígio em um número não menos notável de livros, artigos e papers científicos nesse mesmo campo de pesquisa e reflexão. ${ }^{3}$ Por fim, em virtude do objetivo precípuo do artigo, em lugar da atenção específica a este ou àquele autor, a esta ou àquela obra ou "família intelectual", os esforços analíticos do presente trabalho voltamse a um conjunto mais amplo de ideias, noções e imagens cuja dispersão no pensamento social brasileiro faz-se acompanhar de certa regularidade nos problemas, enunciados e formulações apresentados.

\section{Discurso sociológico e os parâmetros hegemônicos da modernidade}

Em uma conhecida obra, típica de certa agenda de investigação que grassou em meados do século 20, Walt W. Rostow delineia um conjunto de etapas do desenvolvimento em seu esforço de "generalização da marcha da História moderna". ${ }^{4}$ Observe-se que, na caracterização oferecida pelo autor, o desenvolvimento originário das ditas "precondições para o arranco" (a segunda dentre as cinco etapas indicadas) teria ocorrido "de forma bem acentuada, na Europa ocidental do fim do século 17 e início do 18", na esteira da conversão das concepções da ciência moderna em "novas funções de produção" e "num ambiente dinamizado pela expansão paralela dos mercados mundiais e pela concorrência internacional por estes" (Rostow, 1978, p. 18). Naquelas circunstâncias, condições geográficas e naturais favoráveis, acompanhadas de oportunidades comerciais ímpares, às quais se somava certa "estrutura social e política", teriam contribuído para que a Grã-Bretanha se tornasse "a primeira a desenvolver amplamente tais condições prévias” (Rostow, 1978, p. 19). A

\footnotetext{
${ }^{3}$ Não é de estranhar, pois, que tais autores e obras sejam listados em trabalhos individuais e coletâneas, tais quais Introdução ao Brasil: um banquete no trópico, Um enigma chamado Brasil, Um sertão chamado Brasil e Pensadores que inventaram o Brasil, a seu modo sugestivos de seu estatuto "clássico" em nosso universo intelectual. Claro que o reconhecimento desse valor e importância de modo algum equivale a fazer-se presa de suas profecias autorrealizadoras e muito menos endossar, sem maiores reflexões, eventuais apreciações laudatórias ou condescendentes de seus diagnósticos do Brasil.

${ }^{4}$ As etapas arroladas por Rostow são as seguintes: sociedade tradicional, precondições para o arranco (take off), o arranco propriamente dito, a marcha para a maturidade e, por fim, a era do consumo de massa.
} 
despeito do alerta de que esse curso originário jamais votaria a ocorrer de maneira rigorosamente similar, nada parecia demover Rostow de adotar tal "caso" como parâmetro para a caracterização e explicação das peculiaridades encontradas em outros contextos e cenários - como, por exemplo, Ásia, Oriente Médio e África, além de Estados Unidos, Austrália, Nova Zelândia, Canadá e, por fim, a América Latina (Rostow, 1978, p. 31-32).

Seria um erro ver nessas formulações não mais que a expressão das "teorias da modernização" e/ou do ambiente (geopolítico e acadêmico) específico em que vicejaram. ${ }^{5}$ Em verdade, mesmo que de maneira superlativa, As etapas do desenvolvimento economico ampara-se em imagens, preceitos, noções e procedimentos de inferência caros ao próprio discurso sociológico da modernidade amplamente considerado. Em um e outro casos, é flagrante o anseio pela identificação de aspectos tomados por peculiares ao padrão de sociabilidade moderno, invariavelmente retratado como uma ruptura histórica de grande magnitude, ou ainda, um fenômeno sem precedentes na história. Ademais, análises comparativas alimentadas por evidências empíricas coletadas a partir da observação de contextos sociais particulares tendem a desdobrar-se na formulação de categorias e quadros tipológicos generalizantes; ao fim e ao cabo, de maneira mais ou menos sutil, exercícios analíticos dessa natureza resultam na tipificação - ou, se assim se preferir, na classificação de configurações societárias conforme os graus de "desvio" constatados em relação a cenários tomados por modelares da modernidade (ver, por exemplo, Parsons, 1971, p. 122). Interessa-me destacar alguns dos principais termos por meio dos quais esse discurso sociológico codifica o padrão de sociabilidade associado à experiência moderna (Tavolaro, 2005, p.11; Tavolaro, 2014, p. 644-645).

Para iniciar, (1) a diferenciação societária é comumente apontada como um dos traços mais distintivos da modernidade. Conforme essa imagem, a constituição de esferas e âmbitos sociais especializados em torno de tarefas e atividades específicas é indissociável de processos de modernização e complexificação societária. Movidos por expectativas e imperativos próprios, crescentemente autônomos e autorreferenciados, esses âmbitos e esferas sociais seriam regidos por normas e códigos diversos, forjados em estreita relação com os problemas ao redor dos quais se organizam. Na mesma escala de importância, (2) a racionalização é outro processo com frequência vinculado

\footnotetext{
${ }_{5}^{5}$ Certamente Parsons (1971) e Huntington (1975) foram também figuras destacadas naquela cena intelectual. Não menos importante, trabalhos como os de Furtado (2003) e Cardoso e Faletto (1979), como outros produzidos na década de 1960, são expressivos das incontáveis controvérsias e críticas dirigidas às "teorias da modernização".
} 
de maneira estrita à experiência social na modernidade. Ao menos dois aspectos são fortemente associados ao avanço desse processo: primeiramente, concepções de mundo tradicionais, ou seja, aquelas que carecem do amparo de padrões científicos de produção de conhecimento, perdem legitimidade social para fornecer referências cognitivas a respeito de fenômenos do mundo objetivo. Em segundo lugar, esse avanço implica também que referências morais e preceitos éticos, da mesma forma que códigos jurídico-legais, deixam de se amparar em visões de mundo religiosas ou em imagens mágicas do mundo em favor de princípios ético-morais altamente gerais e abstratos, resguardados das especificidades de contextos e formas de vida particulares.

Um terceiro aspecto igualmente tomado por constitutivo do padrão de sociabilidade moderno é (3) a separação estrita entre âmbitos públicos e domínios privados. Nesse caso, sugere-se que as normas, questões e comportamentos que circunscrevem, regem e movem cada uma dessas esferas tornam-se marcadamente distintos. Disso resulta o incentivo à construção, com maior ou menor grau de institucionalidade, de espaços legítimos de contato e comunicação por meio dos quais os dois domínios, resguardados um do outro, possam influenciar-se mutuamente sem prejuízo de seus respectivos códigos, especificidades, imperativos e padrões de organização e funcionamento. Uma modalidade específica de (4) agenciamento, lastreada em certa economia/ organização psíquica, é também associada pelo discurso sociológico ao padrão de sociabilidade moderno. De acordo com essa imagem, a agência moderna ancora-se em uma constituição emocional diferente da encontrada em outras configurações societárias: o agente exemplar da modernidade é dotado de identidade subjetiva centrada, ancorada em uma vida interior única e estável, resistente à transitoriedade das circunstâncias. Disso advém, em primeiro lugar, a fonte fundamental de sua autenticidade, à qual se soma um sentimento de dignidade pessoal imune a eventuais pressões e constrangimentos externos; em segundo lugar, essa estabilidade subjetiva garante ao agente moderno não apenas capacidade de autocontrole e domínio emocional sobre si mesmo como também condições de possibilidade para a adoção de um padrão de conduta metódico e racional, seja em sua vida social, seja em relação ao mundo objetivo a seu redor; sendo, acima de tudo, um sujeito racional, espera-se que ele dê curso às suas emoções apenas em espaços, arenas e ocasiões específicos embora sempre constrangido por regras e normas solidamente internalizadas.

Adicione-se a isso (5) a imagem de ruptura radical entre a cultura e a natureza: conforme esse discurso sociológico, a modernidade teria levado às últimas consequências a separação entre a experiência societária e o mundo natural, ou ainda, entre o reino da liberdade e o reino da necessidade, com claro 
predomínio do primeiro sobre o segundo. Disso decorreria sua capacidade inigualável de manipulação e controle técnico sobre o "ambiente natural" (o mundo objetivo), irresistivelmente subsumido, transformado e remodelado à imagem e semelhança da cultura, assim como condições para o domínio sobre a "natureza interna" (leia-se, o corpo humano e a vida psíquica). Por fim, e não menos importante, (6) atribui-se à experiência social na modernidade uma estrutura espaço-temporal igualmente singular em comparação com outras configurações societárias: perdidos os laços que outrora os faziam confundirse em um cronótopo unitário (hic et nunc), tempo e espaço acabam também por esvaziar-se de aspectos e predicados substantivos derivados do mundo objetivo. Conforme essa concepção, ao se tornar uma categoria cada vez mais neutra, padronizada e abstrata, desassociada das qualidades de localidades específicas, o espaço é imunizado de condicionamentos contextuais; mutatis mutandis, a transformação do tempo em unidade de medida uniforme e abstrata dá-se em favor de uma conotação predominantemente linear e progressiva, com crescente controle sobre a dimensão espacial.

Conforme há pouco sugerido, porquanto num primeiro momento a adoção desses termos tenha o propósito primordial de codificar aspectos tomados por distintivos da sociabilidade moderna, abordagens e programas sociológicos os mais variados acabam, repetidas vezes, por elevá-los à condição de padrões de medida generalizáveis; à luz dessas noções convertidas em parâmetros, outros contextos societários são particularizados, examinados e tipificados. Nesse caso, quanto mais profusa a diferenciação social, quanto mais intensa e abrangente a racionalização, quanto mais marcada a separação público/ privado, quanto mais centrada e estável a economia emocional dos agentes sociais, quanto maior o controle técnico sobre o mundo natural, e quanto mais uniformizada e de-substancializada sua configuração tempo-espacial, mais evidentemente moderna a configuração societária é considerada - donde advém seu estatuto sociológico modelar. Não causa surpresa, pois, que variações (ou, se assim se desejar, "desvios") em relação a esses parâmetros sejam tratados como evidências de incompletude e, ipso facto, de sua condição não-modelar na modernidade (Tavolaro, 2014). A notável abrangência e profundidade da aderência dos principais termos desse quadro de referência entre "clássicos" (Marx [1990], Weber [2002], Durkheim [1982], Simmel, por exemplo), entre seus "epígonos" (dentre os quais, Parsons, Escola de Chicago, Teóricos da Modernização, Elias) bem como entre autores mais "contemporâneos" (Habermas, Luhmann, Bourdieu, Touraine, Giddens, Beck, para citar alguns) - admitidas, é claro, as modulações específicas a cada caso - parece nos autorizar a tomá-lo por hegemônico na produção sociológica. Em verdade, 
conforme também parece sugerir Lynch (2013, p. 731), esse mesmo quadro faz valer seu peso em imagens e retratos do Brasil.

\section{Retratos do Brasil a contrapelo da sociabilidade moderna}

Afinal, qual o alcance das obras de nossos mais prestigiados intérpretes? Com referência a que cenários poder-se-ia atribuir-lhes algum valor heurístico? Se tomadas, stricto sensu, como respostas intelectuais a questões e problemas próprios de uma experiência societária única em seus traços mais essenciais, talvez esta indagação dispensasse maiores controvérsias: assim vislumbradas, contabilizados seus equívocos e sucessos, seus acertos e desacertos - e, por certo, descontadas as obsolescências de tantas quantas âncoras explicativas -, tais obras se resumiriam, na melhor das hipóteses, a jogar luz sobre aspectos exclusivos à sociedade brasileira e cenários congêneres. Em verdade, conforme indiquei anteriormente, apreciações como essa não são de todo estranhas nem mesmo a nossos próprios intérpretes. Mas, a meu ver, esse juízo não exaure as alternativas de interpretação do problema em tela. Outra possibilidade, diametralmente oposta a esta, envolveria explorar o potencial dessas obras para iluminar padrões societários de outros contextos além do brasileiro (bem como de cenários pretensamente congêneres). A bem da verdade, essa rota investigativa não é terra ignota entre analistas desse pensamento. Décadas atrás, Roberto Schwarz enquadrou a questão mais ou menos nos seguintes termos: admitidas nossas originalidades em relação às "sociedades centrais" - das quais forçosamente resultariam adaptações aos produtos espirituais da vida europeia em contato com um cenário em vários aspectos destoante do "centro" -, ainda assim, não se poderia tomar o Brasil como uma realidade autorreferenciada, reclusa diante de outras; de outro modo, constituiríamos uma porção crucial do conjunto, pela qual "passa e se revela a História Mundial." (Schwarz, 2009, p. 80) Ora, para o autor, esse "chão social” peculiar, "em que volta e meia se repete uma constelação na qual a ideologia hegemônica do Ocidente faz figura derrisória”, se revelaria, igualmente, uma maneira de denotar o escopo global de nossas próprias excentricidades (Schwarz, 2009a, p. 78).

Recentemente, Elide Bastos corroborou tal alternativa ao argumentar que "várias questões atualmente colocadas no âmbito das ciências humanas para o entendimento da sociedade foram, de vários modos, objeto de reflexão dos autores brasileiros ao longo dos anos" (Bastos, 2011, p. 52). Para ela, a posição periférica do país no "sistema global" - lugar "onde os conflitos sociais se apresentam em sua pluralidade" -, abriria ao analista uma "perspectiva" que lhe permitiria "visualizar melhor os problemas" (Bastos, 2011, p. 67). Também 
nesse caso, não se trata de posição isolada. Em atenção às proposições de Schwarz, Bernardo Ricupero reitera a hipótese conforme a qual o lugar não hegemônico do Brasil no sistema capitalista mundial constituiria uma situação vantajosa ante o desafio de perceber a complexidade "desse modo de produção" (Ricupero, 2013, p. 529) - o que, ademais, estimularia um viés crítico, à sua vez sugestivo da possibilidade da experiência periférica problematizar aquilo que, no "centro", é assumido como dado (Ricupero, 2013, p. 530). Nesses mesmos passos, João Maia percebe em certa produção intelectual brasileira a "versão dependentista do marxismo" - o anseio de retratar a periferia, não como mero lugar para onde correm as águas oriundas do "centro", mas sim como uma experiência capaz de refletir a respeito da modernidade de maneira verdadeiramente mundial (Maia, 2009, p. 163-164). Em sintonia com Bastos (2011, p.67), o autor sustenta que esse reenquadramento interpretativo tem importantes implicações para a própria maneira como situamos o pensamento brasileiro e suas formulações: não mais encapsulados nos contornos da sociedade nacional (Maia, 2011, p.81), mas "como parte integrante de um movimento de ideias global" (Maia, 2011, p. 87) - que, além disso, revela-se potencialmente pertinente "para estudiosos e pesquisadores das mais variadas regiões do mundo" (idem). Já Adélia Miglievich, a propósito de Darcy Ribeiro, identifica em trabalhos seus "insights que [...] derivam em adesões claras às ideias de uma modernidade plural" (Ribeiro, 2011, p.15), além de revelar "a coetaneidade dos povos ditos avançados e dos atrasados" (Ribeiro, 2011, p. 27). Por fim, Victor Lage sustenta que "As ideias fora do lugar aqui jogam luz sobre as ideias fora do lugar lá; e, o que é mais, a discrepância brasileira joga luz sobre o processo global' (Lage, 2016, p. 45). ${ }^{6}$

Essas proposições indicam uma vereda promissora. Mas não se pode explorá-la sem antes contemplar outra controvérsia: conforme Lage (2016) sugere, trata-se dos riscos envolvidos em se estabelecer uma associação necessária entre "virtudes modernas" e "atraso" - ou, nos dizeres do próprio autor, "como se a condição 'periférica' proporcionasse, por definição (espaço-temporal), o privilégio de um olhar diferente da modernidade em relação ao 'centro' e a possibilidade de se pular estágios dentro do caminho da modernização” (Lage, 2016, p.48). É problemático, para dizer o mínimo, assumir já de partida que "sociedades não-modelares", por essência de sua condição, dispõem de predicados capazes de alçá-las mais rapidamente, à

\footnotetext{
${ }^{6}$ Observo que várias das passagens de Schwarz (2009a), Ricupero (2013) e Maia $(2009 ; 2011)$ supracitadas são também destacadas e comentadas por Lage $(2016$, p. 45, 48-49, 85), cujas reflexões acerca desses problemas interessam ao presente artigo.
} 
maneira de atalhos, ao "presente" da modernidade - dentre outras razões porque esta seria a reafirmação de um olhar reificado, igualmente ancorado em certa noção simplista de "progresso", a mesma que a princípio se pretenderia desmobilizar. Que fique claro, pois: não se quer, de modo algum, celebrar positividades modernas supostamente adormecidas no "atraso". A argumentação segue rota diversa. Nas pegadas de Schwarz (2009a), Bastos (2011), Maia (2011), Ribeiro (2011), Ricupero (2013), Tavolaro (2005; 2014) e Lage (2016), quer-se tão somente sugerir que existe um potencial heurístico merecedor de atenção em formulações que oferecem retratos e análises de "cenários não-modelares da modernidade": por força de sua tarefa, tais elaborações trazem a lume aspectos e dimensões da modernidade invisibilizados ou insuficientemente contemplados em narrativas sociológicas hegemônicas; tal obumbramento (parcial ou total) deriva do fato dessas narrativas com frequência vislumbrarem esses aspectos e dimensões como estranhos à experiência moderna propriamente dita ou, no melhor dos casos, como exclusivos às chamadas "configurações societárias periféricas".

Ora, a meu ver, esses mesmos aspectos e dimensões sub-representados nas narrativas sociológicas hegemônicas podem ser identificados em obras de nossos "clássicos" por meio de um exercício de "destilação fracionada" de características mais comumente associadas à sociedade brasileira. ${ }^{7}$ Admitidas as irredutíveis especificidades de cada uma delas, ao trazerem à luz facetas da experiência moderna subestimadas ou de todo desconsideradas por essas narrativas, seus retratos do Brasil podem lançar suspeitas sobre as ambições e adequações daquele enquadramento teórico-conceitual hegemônico. Veja-se, pois: primeiramente, (1) é disseminada entre obras "canônicas" de interpretação do país a imagem da sociedade brasileira como uma configuração na qual política, economia, cultura, vida familiar, religião, ciência, dentre outros âmbitos de sociabilidade, jamais teriam chegado a se constituir em esferas autônomas ou relativamente autônomas, regidas por códigos e lógicas de funcionamento próprios, especializadas na realização de tarefas específicas. Tratar-se-ia, pois, de um cenário em que, à diferença das sociedades ditas "centrais", Estado, mercado, sociedade civil, família, cultura, religião, vida intelectual, além de outras esferas de sociabilidade, permaneceriam imbricadas,

\footnotetext{
${ }^{7}$ Vale dizer, conforme anteriormente observado, não se pretende subestimar a importância dos predicados de cada uma dessas obras, das particularidades das "famílias intelectuais" que as produziram ou mesmo das diferenças geracionais que as separam (Liedke, 2005; Brandão, 2007). No entanto, considerados os propósitos prioritários do artigo, almejo tão somente sublinhar seu denominador comum, ou se assim se preferir, certa regularidade que percorre a vasta dispersão do pensamento brasileiro.
} 
sobrepostas, estruturalmente acopladas, a ponto de verem confundidos seus escopos de ação, seus imperativos e funções, em prejuízo do cumprimento ótimo de suas atribuições específicas (Tavolaro, 2005; 2013; 2014). Todos esses traços caracterizariam um quadro marcado por níveis de diferenciação social incompatíveis com o estatuto de uma ordem social verdadeiramente moderna. ${ }^{8}$

É também frequente entre nossos intérpretes o retrato do Brasil como (2) uma configuração societária em que as fronteiras entre âmbitos públicos e privados são fluidas e permeáveis. Entrelaçados, por vezes até justapostos, a todo momento esses âmbitos se influenciariam mutuamente, sem mediações capazes de disciplinar suas relações e, desse modo, preservar suas respectivas identidades. Por vezes, enfatiza-se o fato das instituições públicas dessa sociedade serem moldadas à semelhança de domínios domésticos; em outras ocasiões, alude-se à sua maior susceptibilidade às interferências de interesses privados de segmentos sociais em posições elevadas de poder; menção também é feita à preponderância de códigos de sociabilidade primários, em especial aqueles da família patriarcal, na conformação dos domínios privados e de interesses particulares (Tavolaro, 2005; 2013; 2014). Em todos os casos, o resultado seria uma vida pública infensa a regras de conduta e normas impessoais assim como à participação paritária em instâncias decisórias e processos racionais de formação da vontade coletiva. ${ }^{9}$

Não menos incomum é (3) o retrato desta sociedade como uma configuração na qual processos de secularização não teriam se consumado com a mesma abrangência e profundidade observadas nas chamadas "sociedades centrais"; esse lapso traria implicações decisivas sobre o próprio funcionamento do aparato político-administrativo, em especial sobre as bases de sua legitimação na sociedade mais ampla (Tavolaro, 2005; 2013; 2014). A isso soma-se a imagem de que elementos mágico-religiosos permaneceriam atuantes no tecido social, de modo a informar as visões de mundo de diversos segmentos da população, suas modalidades de atuação nos espaços públicos e privados, as maneiras como interpretam o ordenamento jurídico, suas expectativas mútuas de comportamento assim como suas condutas e experiências cotidianas nas mais variadas esferas de sociabilidade. ${ }^{10}$

\footnotetext{
${ }_{8}^{8}$ Ver Nabuco, 2000, p. 128; Torres, 1982, p. 147; Vianna, 1987, p. 117-119; Costa Pinto, 1973, p. 246-247; Hollanda, 1936, p. 11-12; Prado Jr., 2011, p.332; Faoro, 2001, p. 789; Ianni, 1978, p. 204; Fernandes, 2006, p. 312-313.

9 Ver Nabuco, 2000, p. 146-147; Bomfim, 1993, p. 141; Torres, 1982, p. 94; Vianna, 1987, p. 49; Hollanda, 1936, p.99-101; Prado Jr., 2011, p.341-342; Freyre, 1996, p. XC; Leal, 2012, p.5760; Faoro, 2001, p. 711.

${ }^{10}$ Ver Cunha, 1981, p. 138; Torres, 1982, p.119; Hollanda, 1936, p. 106-110; Prado Jr., 2011, p. 348-349; Faoro, 2001, p. 828; Fernandes, 2008a, p. 53; Ianni, 1978, p. 57.
} 
Tais retratos fazem referência, ainda, à (4) existência de certo arranjo espaço-temporal no Brasil diverso daquele com maior frequência associado à modernidade. Ao contrário, pois, da crescente abstração, esvaziamento e padronização da experiência tempo-espacial atribuído à vida moderna, não são poucas as interpretações da formação brasileira em que os predicados do ambiente físico são elevados ao estatuto de condicionantes da vida social do país; dessa feita, aspectos substantivos do espaço físico são apontados como variáveis capazes de influenciar a organização de suas instituições, os padrões comportamentais dos agentes, o universo simbólico predominante bem como a estrutura mental dos indivíduos. Mutatis mutandis, fala-se também de uma configuração temporal diferente daquela encontrada entre as ditas "sociedades centrais"; nesse caso, os traços mais distintivos seriam, de um lado, sua não-linearidade - expressão maior de uma composição heteróclita, marcada por combinações variadas e circunstanciais entre passado, presente e futuro - e, de outro, seu vínculo estreito com aspectos culturais, simbólicos e materiais de situações e experiências societárias bastante específicas. ${ }^{11}$

Outro aspecto também considerado característico da experiência societária brasileira é (5) certa organização/economia psíquica identificada em parcelas expressivas de sua população, entre as quais predominariam impulsos emocionais em detrimento do controle racional da existência (Tavolaro, 2014). Nesse particular, parece prevalecer entre nossos "clássicos" a imagem conforme a qual brasileiros e brasileiras, via de regra suscetíveis às manifestações de suas pulsões emocionais - em diferentes ocasiões, esferas e arenas de convívio - carecem de uma vida psíquica dotada de estabilidade e profundidade subjetiva; tal lacuna se refletiria na ausência de identidade pessoal unitária e centrada, bem como em sua incapacidade para impor limites à experiência emotiva. Disso resultaria um padrão comportamental incerto, descontínuo, adverso ao empreendedorismo econômico metódico e à atuação racional em processos de deliberação política, uma vez que marcado por instabilidade, resistência à conduta disciplinada, predisposto às variáveis pressões do meio (social e natural) além de avesso a referências normativas impessoais. ${ }^{12}$

\footnotetext{
${ }^{11}$ Ver Romero, 1949, p. 274-277; Cunha, 1981, p.60; Vianna, 1987, p. 15-16; Prado Jr., 2011, p. 11; Freyre, 2000b, p. 32; Ramos, 1996, p. 139; Costa Pinto, 1978, p. 53-55; Faoro, 2001, p. 823; Fernandes, 2008a, p. 60-61; Ianni, 1978, p. 211.

${ }_{12}$ Ver Nabuco, 2000, p. 137 e 150; Romero, 1949, p. 274; Cunha, 1981, p. 77; Torres, 1982, p. 131; Vianna, 1956, p. 136 e 139; Prado, 2012, p.96; Hollanda, 1936, p. 103-105; Freyre, 2006, p. $20-$ 21; Prado Jr., 2011, p. 373; Ramos, 1996, p. 64; Fernandes, 2008b, p. 44-45.
} 
Por fim, fala-se desta como (6) uma sociedade quase sempre sujeita às influências do meio natural, como se o universo cultural e a vida social jamais tivessem logrado romper, de maneira clara e definitiva, seus laços com a natureza; disso resultaria seu baixo grau de controle, de domesticação, de manipulação técnica e de sujeição racional do ambiente físico. Ademais, essa permeabilidade entre a vida social no Brasil e o mundo natural ajudaria a explicar não apenas a demora com que essa sociedade tomou as rédeas de seu vasto território, mas também a proximidade cotidiana, embora nem sempre harmônica, entre amplos segmentos da população e a natureza. Ainda conforme esses retratos preponderantes do país, não raro a cultura popular confere atributos anímicos a entes naturais (orgânicos e inorgânicos), razão pela qual parecem participar ativamente tanto do mundo objetivo quanto das experiências humanas coletivas e subjetivas. $\underline{13}$

A esses aspectos, tratados em obras "clássicas" de interpretação do Brasil como pertinentes à sociedade brasileira, o discurso sociológico hegemônico da modernidade reserva um estatuto teórico assaz conhecido: na maior parte das vezes, des-diferenciação social, não-secularização, porosidade entre público/privado, subjetividade descentrada, não-linearidade espaço-temporal e fluidez entre sociedade/natureza são apontados como evidências de uma experiência moderna incompleta, ou ainda, como manifestações de um padrão de sociabilidade permeado por elementos estranhos ao ordenamento social moderno. Por vezes, tais aspectos são tratados como vestígios ou resquícios de experiências tradicionalistas, atuantes nos valores, instituições, padrões estéticos e comportamentais, universos mentais e ordens normativas de "sociedades em transição"; não raro, constituiriam obstáculos a uma vivência plenamente moderna. Mas mesmo quando codificados como subprodutos mais ou menos recentes de transformações sociais contemporâneas, a seu modo vinculados à própria dinâmica moderna, aquele discurso hegemônico pende a dissociá-los por completo das chamadas configurações "modelares" da modernidade. Num e noutro casos, prevalece o juízo conforme o qual a sociedade brasileira (e contextos análogos) apresenta evidentes descompassos em relação às ditas "sociedades centrais", muito embora permaneça suscetível às referências culturais, intelectuais, comportamentais, estéticas, normativas, institucionais etc. dessas últimas.

${ }^{13}$ Ver Nabuco, 2000, p. 163; Romero, 1949, p. 259-277; Cunha, 1981, p.97; Vianna, 1956, p. 167; Vianna, 1987, p. 121; Prado, 2012, p.42-45; Hollanda, 1936, p.61-62; Freyre, 1976, p.67-70; Ramos, 1996, p. 60. 


\section{Pensamento social brasileiro: elementos de uma imaginação contra-hegemônica}

É possível sugerir um tratamento sociológico diverso para essas imagens - não como propriedades e expressões exclusivas de configurações societárias específicas (periféricas, em desenvolvimento, do Sul, ex-coloniais etc.), mas como "retratos não-modelares" da própria modernidade, a seu modo capazes de iluminar, com alcance epistemológico e teórico mais ampliado, facetas da experiência moderna subapreciadas pelo discurso sociológico hegemônico. Nesse caso, faz-se necessário desafiar aqueles parâmetros há pouco delineados. Vale sublinhar, também aqui, de forma alguma encontramo-nos em território inexplorado. De outro modo, a teoria social contemporânea tem se relevado pródiga em formulações e programas de investigação críticos a esses mesmos enquadramentos. Refiro-me, por exemplo, à extensa e diversificada literatura produzida sob as designações modernidade global (Domingues, 2003; Schmidt, 2012), modernidades múltiplas (Eisenstadt, 2000; 2010; Göle, 2000), pós-colonialidade (Bhabha, 2010; Chakrabarty, 2000), epistemologias do Sul (Sousa Santos, 2009) e decolonialidade do saber/poder (Dussel, 2005; Mignolo, 2000). Foge ao escopo deste artigo considerar os termos de cada uma dessas modalidades de crítica ao discurso da modernidade. Importa-me o fato de que, admitidas e contabilizadas suas especificidades (por certo, em muitos casos irreconciliáveis), restam algumas preocupações comuns que apontam justamente para a existência de "experiências não-modelares" no quadro contemporâneo. Dito de outro modo, considerados seus embasamentos epistemológicos, seus contornos teóricos bem como as ambições programáticas dessas abordagens, não há dúvidas de que estamos diante de maneiras distintas de interpelar os fatos e a própria semântica da modernidade. Ainda assim parece subsistir um conjunto compartilhado de preocupações (Tavolaro, 2016).

Para iniciar, (1) coloca-se em questão a própria unidade de análise com frequência adotada por formulações que se amparam em categorias caras ao discurso sociológico: esses programas insinuam que a sociedade nacional deve perder prioridade metodológica em favor de novos níveis de circunscrição do objeto (o local, o regional, o supranacional, o global etc.); em certas ocasiões, chega-se mesmo a conferir primazia explicativa às suas múltiplas conexões, vínculos e relações, às quais se atribui peso determinante na definição dos contornos da cena contemporânea. Em segundo lugar, (2) problematiza-se certa unidirecionalidade (e, em algumas ocasiões, também a estrutura temporal que lhe é subjacente) que, de maneira mais ou menos explícita, orienta a tessitura de narrativas sociológicas mais convencionais: há um expresso 
desconforto em relação a retratos que imputam linearidade e progressividade aos desdobramentos históricos e transformações econômicas, culturais, institucionais, epistemológicas, comportamentais etc. associados à experiência moderna. Vale dizer, esse mal-estar não se restringe às imagens que conferem antecedência temporal/formal às "configurações modelares" em detrimento de "contextos não-modelares"; na verdade, abundam ocasiões em que esse mesmo desconforto é dirigido a retratos que reforçam a precedência teórica e metodológica comumente outorgada a segmentos sociais "estabelecidos" (como se estes fossem portadores autênticos e originários de padrões e formas de vida modernos) em relação a "grupos subalternizados/marginalizados" (isto é, aqueles setores sociais "mal ajustados" aos padrões e formas de vida associados à modernidade). Não por acaso, (3) coloca-se igualmente sob suspeita o real alcance e capacidade da estrutura teórico-conceitual daquela narrativa para apurar os pretensos lapsos e descompassos observados em "experiências societárias não-modelares"; ato contínuo, (4) levanta-se dúvidas também acerca da adequação das imagens especulares cultivadas a respeito dos "Outros" da modernidade. ${ }^{14}$ Chega-se mesmo a (5) reivindicar protagonismo para experiências societárias "marginais" ou "periféricas" na cena moderna, seja em relação à vivência criativa e original de referências institucionais, valorativas, comportamentais etc. atribuídas à modernidade, como à sua capacidade para produzir e irradiar novos sentidos, significados e narrativas a respeito do moderno. Ao fim e ao cabo, tais abordagens e programas parecem sugerir que (6) o quadro societal contemporâneo constitui-se e renova-se continuamente a partir de um conjunto de referências (cognitivas, valorativas, institucionais) e de experiências societárias bem mais diversas e complexas do que supõe o imaginário hegemônico da modernidade (Tavolaro, 2016).

Enfim, qual a relevância desse debate para o presente artigo? Considerese a conjectura anteriormente apresentada: se por um lado, é legítimo afirmar com boa dose de segurança que as imagens do Brasil delineadas por alguns de nossos mais celebrados intérpretes erguem-se apoiadas sobre parâmetros caros àquele imaginário hegemônico da modernidade - o que, prima facie, apenas concorreria para reafirmar o alardeado hiato entre a sociedade brasileira e os chamados "contextos modelares" -, por outro, em meio às suas tentativas de oferecer explicações e conferir sentidos a uma experiência a seu ver descompassada desses "contextos modelares", suas principais obras acabam também por esboçar elementos para uma narrativa contra-hegemônica. Vale ${ }^{14}$ Dentre as imagens especulares desse imaginário, destacam-se civilização/barbárie, modernidade/tradição, sociedade industrial/sociedade agrária, América Anglo-saxônical Latina, Ocidente/Oriente, mundo desenvolvido/subdesenvolvido, primeiro mundo/terceiro mundo, centro/periferia, Norte/Sul. 
dizer, não se está diante de conceitos e noções sistematicamente integrados e articulados a narrativas formuladas com o propósito deliberado de enquadrar a experiência moderna de modo radicalmente diverso de abordagens correntes em seu tempo. De outro modo, tais elementos aparecem de maneira difusa e residual. ${ }^{15}$ Ora, as abordagens e programas de reflexão há pouco aludidos convêm a este artigo na medida exata em que seus desafios ao vigor, ao alcance e à adequação do discurso sociológico hegemônico da modernidade auxiliamnos a também identificar, nas chamadas obras "clássicas" de interpretação do Brasil, insights e formulações sugestivas de pontos de vista, imagens, noções e parâmetros alternativos acerca da própria experiência moderna.

Sob tal perspectiva, o primeiro desafio que esses retratos e imagens do país sugerem àquele quadro de referência diz respeito ao suposto da diferenciação social: longe de incomum, a imbricação entre esferas e domínios sociais diversos parece ser recorrente não apenas em "configurações nãomodelares" mas também em "cenários modelares" (Mann, 1996; Wittrock, 2000). Somos, assim, convidados a considerar a ocorrência não de uma única, mas de diferentes modalidades de articulação entre a política, a economia, a cultura, a religião, a família, a sociedade civil e outros âmbitos, no seio das próprias sociedades complexas; assim surpreendidas, tais esferas deixam de se apresentar como domínios autorreferenciados, resguardados de influências "externas" e regidos de maneira estrita por normas e códigos específicos. $\mathrm{Na}$ contramão, pois, dessa imagem-ideal projetada sobre a modernidade, parecem proliferar situações e experiências contemporâneas marcadas pela confusão de atribuições envolvendo domínios sociais diversos. Algo análogo pode ser dito acerca do tipo de relação público/privado na maior parte dos casos adotado como modelar do ordenamento moderno: além de, em diferentes circunstâncias, exibirem certa variedade de significados para diferentes segmentos sociais, parece pouco adequado codificá-las como

\footnotetext{
${ }^{15}$ Com alguma liberdade, inspiro-me na ideia de "categorias residuais" empregada por Parsons (1968, p. 16-20) em outro contexto intelectual. Adapto essa ideia para tratar de certas imagens, noções e referências empíricas dispersas em obras de interpretação da formação brasileira que parecem sugerir perspectivas e pontos de vista contra-hegemônicos da experiência moderna. É certo que, na maior parte dos casos, tais obras adotam parâmetros que reforçam a imagem de descompasso da sociedade brasileira vis-à-vis "configurações modernas modelares" racionalização, diferenciação social, separação público/privado, disjunção cultura/natureza, subjetividade centrada e tempo-espaço linear e progressivo seriam parâmetros indicativos desses lapsos e hiatos. Isso posto, a meu ver, ao se debruçarem sobre fatos e fenômenos mal ajustados a "categorias positivamente definidas" (Parsons, 1968, p. 17) desse imaginário hegemônico, por tabela, essas obras - e as ideias do Brasil nelas inscritas - acabam por indicar perspectivas alternativas da própria modernidade. Empregando-se a terminologia de Parsons, trata-se, nesse caso, de "noções residuais", que insinuam interpelar e desafiar categorias e parâmetros "positivamente definidos".
} 
esferas de sociabilidade rigorosamente apartadas, cada qual resguardada das ingerências, lógicas de funcionamento e imperativos diversos dos seus (Turner, 1990). De outro modo, os inúmeros formatos e combinações entre âmbitos públicos e privados observados em contextos societários complexos ("centrais" e "periféricos") apontam para a existência de trânsitos e influências constantes, envolvendo códigos de sociabilidade muitas vezes associados de maneira exclusiva ao ambiente doméstico-familiar (ou mesmo à privacidade de cada indivíduo) e a instituições públicas (o Estado, o mercado bem como organizações da sociedade civil).

Retratos do Brasil podem também levantar suspeitas a respeito do vínculo necessário que em regra se estabelece entre modernização e secularização: ao contrário do que normalmente se supõe, não parece satisfatório tratar a resiliência da religião e de outras visões de mundo não-racionalizadas em âmbitos privados e arenas públicas como mero resquício de tradicionalismo. Longe disso, é preciso admitir que, ao invés de traço específico de sociedades ditas "duais" ou "em transição", a influência de concepções e de organizações religiosas na conduta cotidiana dos indivíduos, com impactos determinantes sobre suas identidades pessoais e coletivas, assim como no funcionamento de instituições públicas, é notória também em uma ampla gama de contextos societários "modelares" (Casanova, 1994). Não menos importante, aquelas imagens delineadas por intérpretes da formação brasileira levam-nos a cogitar acerca da expressiva variedade de experiências subjetivas observada na cena moderna: selves plurais, múltiplas identidades, predomínio de apreciações afetivas sobre orientações racionais, com impactos significativos nas performances e atuações dos indivíduos em esferas e domínios sociais distintos (economia, política, família, sociedade civil etc.) são apenas alguns dos fenômenos que nos convidam a colocar em xeque a imagem monocromática em geral associada ao sujeito racional moderno (Hall, 2006).

A isso se soma a problematização dos parâmetros espaço-temporais com frequência adotados pelo discurso sociológico: os esforços interpretativos de nossos "clássicos" também insinuam que a estrutura progressivo-linear de uma temporalidade padronizada e de-substancializada é apenas uma dentre outras modalidades encontradas na cena atual (Chatterjee, 2008; Gumbrecht, 2015). Algo similar pode ser dito acerca da concepção abstrata e esvaziada de espaço: ela não consegue aquilatar a relevância que aspectos qualitativos, vinculados a predicados situacionais de localidades específicas, demonstram ter nas percepções, valores e experiências (subjetivas e coletivas) cotidianas e extracotidianas de segmentos diversos de sociedades contemporâneas (Escobar, 2005). Por fim, aqueles "retratos e imagens não-modelares" 
indicam-nos a existência (prática e imagética) de fronteiras mais fluidas e permeáveis entre o mundo sociocultural e o ambiente natural no seio das próprias sociedades modernas, muito mais do que parecem sugerir olhares sociológicos convencionais (Eckersley, 1992; Escobar, 2005).

Mas caso se pretenda explorar em maior profundidade esse potencial contra-hegemônico inscrito nas imagens e retratos do Brasil há pouco mencionados, há que se considerar outra sugestão que se insinua em nossas obras "clássicas", a saber: a noção conforme a qual a própria existência dessa sociedade sempre esteve associada aos efeitos e qualidades emergentes de seus entrelaçamentos e conexões com outras experiências e contextos societários. Não se trata de negar a enorme frequência com que tais obras mobilizaram esforços no sentido de identificar aspectos e traços que, em maior ou menor medida, responderiam pelos descompassos do país em relação a "cenários centrais"; bem sabemos que, em situações limítrofes, chegou-se mesmo a retratá-la como uma configuração notadamente original, portadora de qualidades irredutíveis a quaisquer outras. Nessa direção, abundam ocasiões em que meio natural (Romero, 1949; Cunha, 1981; Freyre, 2000a), raça (Romero, 1949; Cunha, 1981; Vianna, 1956; Freyre, 2000a), aspectos históricos e culturais (Bomfim, 1993; Hollanda, 1936; Freyre, 2000b), economia (Prado Jr., 2011; Furtado, 2009; Ramos, 1996; Fernandes, 2006; Ianni, 1978), política (Nabuco, 2000; Bomfim, 1993; Torres, 1982; Vianna, 1987; Leal, 2012; Faoro, 2001), dentre outras variáveis, combinadas ou não entre si, foram arroladas com o intuito de explicar suas pretensas singularidades ou, de maneira mais branda, de apurar a propalada defasagem do Brasil em relação aos "centros dinâmicos da modernidade". Dito isso, é preciso também frisar que não deixou de haver ocasiões em que tal experiência societária, bem como alguns de seus traços característicos, foi vinculada a fatores que excediam suas fronteiras estritas. Nesses casos, propriedades estanques e/ou específicas imputadas a essa sociedade aparecem suavizadas à sombra de imagens mais fluidas e dinâmicas nas quais ganham relevo as múltiplas conexões que atravessam sua história (Romero, 1949, p. 296-298; Bomfim, 1993, p. 49; Hollanda, 1936, p. 15; Prado Jr., 2011, p. 19-22; Faoro, 2001, p. 130; Furtado, 2009, p. 67-68; Costa Pinto, 1978, p. 59 e 61; Ramos, 1996, p. 139-140; Fernandes, 2006, p.264-266; Ianni, 1978, p. 1978). Sob esse ângulo, na contramão daquele discurso sociológico hegemônico, essas formulações voltam a ensaiar um enquadramento alternativo: em primeiro lugar, somos convidados a repensar as fontes generativas de propriedades atribuídas à sociedade brasileira; ademais, somos incitados a refletir a respeito das reais especificidades desses predicados; por fim, somos chamados a reavaliar o estatuto analítico da própria sociedade 
brasileira - isto é, sua condição de unidade de análise - em favor dos complexos de relações em que, desde suas "mais remotas origens", esteve enredada.

De maneira análoga, esses problemas extrapolam os confins do pensamento brasileiro e nos conduzem a agendas de reflexão que também animam a teoria social contemporânea. Refiro-me, em particular, a dois conjuntos de debates que guardam certa afinidade: o primeiro deles crítico ao estatuto teórico-metodológico da nação e/ou de outras unidades estritas de análise que porventura assumem o seu lugar (Bhabha, 2010; Beck, 2000; Chernillo, 2011; Elias, 1978b; Monterescu, 2013; Wimmer and Schiller, 2002); o segundo preocupado com as implicações da mudança de ênfase teórica e epistemológica em favor do caráter relacional/processual da experiência social (Dépelteau, 2013; Donati, 2013; Elias, 1978a; Emirbayer, 1997; Prandini, 2015; Powell and Dépelteau, 2013; Subrahmanyam, 1997; Therborn, 2003). A meu ver, está claro que um discurso contra-hegemônico da modernidade exige que se reavalie a tendência generalizada com que as "estruturas epistêmicas e os programas das ciências sociais mainstream" aparecem acoplados à "experiência da formação do estado-moderno" (Wimmer and Schiller, 2002, p. 302-303); ${ }^{16}$ mais que isso, porém, é preciso também examinar a propensão observada nas ciências sociais para adotar configurações societárias estritamente circunscritas (não apenas a "nação", mas também o "1º Mundo", a "Periferia", o "Sul", as "sociedades desenvolvias", o "Ocidente" etc.) como entidades analíticas insuspeitas, portadoras de qualidades especiais, capazes de fazê-las resistir às pressões conformadoras das conexões em que se encontram enredadas. Ora, ao fim e ao cabo, considerados os propósitos precípuos deste artigo, é mais provável que a maneira mais produtiva de "desconectar a noção de 'modernidade' de uma trajetória europeia particular" (Subrahmanyam, 1997, p. 744-745) seja justamente abrir mão da perspectiva das "histórias comparadas" - aquela apoiada sobre "unidades geográficas convencionais de análise" - em proveito da abordagem das "histórias conectadas" (idem). ${ }^{17}$

\footnotetext{
${ }^{16}$ Nesse sentido, há que se levar em conta a advertência de que "as fronteiras dos Estados nacionais se sobrepõem de maneira desigual a populações, territórios, padrões de produção e consumo, identidades culturais, compromissos emocionais coletivos, e assim por diante, enquanto que 'interações intersticiais', tanto dentro como através dessas unidades delimitadas, também repetidamente desmentem essas últimas como entidades unitárias" (Emirbayer, 1997, p. 295).

${ }^{17}$ Por essa razão, o autor prefere referir-se à modernidade como "uma mudança mais ou menos global, com muitas fontes e raízes e - inevitavelmente - muitas formas e significados diferentes" (Subrahmanyam, 1997, p.736-737). Nessa mesma direção, vale recordar as reflexões de Therborn (2003, p. 295) a respeito dos entrelaçamentos da modernidade com a "tradição" assim como com aspectos de natureza "geopolítica" (envolvendo a influência mútua de diferentes "caminhos sociopolíticos através e em direção à modernidade").
} 


\section{Considerações finais: para uma abordagem relacional da modernidade}

Sob o impacto de tais formulações, a consideração daquelas sugestões inscritas nos "clássicos" do pensamento brasileiro abre ao menos três portas profícuas para uma abordagem sociológica contra-hegemônica da modernidade: (a) em primeiro lugar, a contrapelo de certo modelo de sucessão/imitação (ver Franco, 1976, p.61) envolvendo unidades analíticas fixas (sociedades nacionais ou em outras escalas) dotadas de propriedades singulares, somos instados a suspeitar do estatuto originário e autossuficiente imputado a algumas experiências via de regra elevadas à condição "modelar" da modernidade (o "Centro", a "Metrópole", o "Ocidente", as "sociedades industriais desenvolvidas", o "Norte", o "10 Mundo" etc.); em contrapartida, somos também convidados a repensar o dístico de "replicador tardio de formas modernas autênticas", em geral afixado às chamadas "sociedades em transição" (ou ainda à "Periferia", à "Colônia", ao "3은 Mundo", ao "Oriente", ao "Sul" etc.). Nesse caso, ao invés de interpelá-las de maneira isolada - como se dispusessem de qualidades exclusivamente suas -, experiências societárias "modelares" e "não-modelares" devem ser retratadas como partícipes de complexos de relações irredutíveis às propriedades e características de qualquer uma de suas partes individuais. Disso se segue que (b) em lugar de se atribuir prioridade explicativa ao quociente aspectos endógenos/fatores exógenos (sejam eles o meio natural, a composição étnico-racial, a cultura, a economia, o universo mental, a história local etc., combinados ou não entre si), maior atenção deve ser conferida à influência e ao impacto conformador das próprias relações e processos que conectam e entrelaçam tais contextos e experiências diversas. ${ }^{18}$ Por fim, (c) contabilizados os efeitos epistemológicos das assimetrias geopolíticas, simbólicas, econômicas, militares etc. constitutivas da modernidade, somos também convidados a refletir criticamente sobre as valias teóricas e os estatutos sociológicos desiguais comumente emprestados, não raro de maneira a priori, a "contextos modelares" e a "experiências não-modelares".

Esse reenquadramento do discurso sociológico à luz dos entrelaçamentos, conexões e complexos de relações societárias da modernidade ajuda-nos a

\footnotetext{
${ }^{18}$ Para Elias (1978b, p. 168), por exemplo, seja no caso dos países do "Terceiro Mundo" ou de países altamente industrializados, "os processos endógenos de desenvolvimento social permanecerão incompreensíveis e inexplicáveis a não ser que o desenvolvimento do sistema de estados seja ao mesmo tempo levado em consideração. Pois cada estado-sociedade em particular está enredado no sistema de estados".
} 
diluir aquele desconforto acerca das origens pretensamente estrangeiras dos esquemas mentais, referências institucionais, padrões normativos e estéticos encontrados no Brasil: além de múltiplas as suas fontes, pode-se afirmar que os quadros de referência modernos oferecem indicadores e parâmetros (epistemológicos, institucionais, comportamentais, ético-morais, estéticos etc.) para uma enorme variedade de contextos e experiências societárias contemporâneas ("modelares" e "não-modelares"). Sob essa perspectiva, muitos dos predicados identificados na sociedade brasileira - dentre os quais a imbricação de esferas sociais, a permeabilidade entre público/privado, a resiliência de concepções de mundo não racionalizadas, as múltiplas configurações tempo-espaciais, pluralidade identitária e descentramento da subjetividade, além da porosidade entre sociedade/natureza - podem ser vistas de um ângulo diverso: ao contrário de propriedades idiossincráticas decorrentes de inconfundíveis especificidades societárias, pode-se tomá-las como representativas de facetas e aspectos da modernidade subapreciados pelo discurso sociológico. Nesse sentido, longe de adstritas à realidade nacional, obras "clássicas" do pensamento brasileiro auxiliam a ampliar e diversificar os horizontes de compreensão e codificação da própria experiência moderna. Dito de outro modo, ainda que de maneira residual e não necessariamente em conformidade com suas motivações e planos originais, ao menos algumas das mais celebradas obras de interpretação do Brasil oferecem retratos, noções, categorias e ideias que contribuem para um imaginário contra-hegemônico da modernidade.

\section{Referências}

BASTOS, Élide. Atualidade do pensamento social brasileiro. Sociedade e Estado, v. 26, n. 2, p. 51-70, $2011<10.1590 /$ S0102-69922011000200004>.

BASTOS, Elide; BOTELHO, André. Horizontes das Ciências Sociais: pensamento social brasileiro. In: Carlos Martins; Heloisa Martins (orgs.). Horizontes das ciências sociais no Brasil. São Paulo: Anpocs, 2010. v. 1, p. 475-496.

BECK, Ulrich. What is globalization? Malden, MA: Polity Press, 2000.

BHABHA, Homi. O local da cultura. Belo Horizonte, Editora Ufmg, 2010.

BOMFIM, Manoel. A América Latina: males de origem. Rio de Janeiro, Topbooks, 1993.

BOSI, Alfredo. Origem e função das idéias em contextos de formação colonial. In: Centro de Estudos Brasileiros/Embaixada do Brasil em Roma (org.). Pensamento Brasileiro. Palermo: Renso e Rean Mazzone editori, 1995. p. 17-31.

BOTELHO, André; SCHWARCZ, Lília. Um enigma chamado Brasil: 29 intérpretes e um país. São Paulo: Cia. das Letras, 2009. 
BRANDÃO, Gildo. Linhagens do pensamento politico brasileiro. São Paulo: Aderaldo \& Rothschild Editores, 2007.

CANDIDO, Antonio. Iniciação à literatura brasileira. Rio de Janeiro: Ouro sobre azul, 2010.

CARDOSO, Fernando H. Pensadores que inventaram o Brasil. São Paulo: Cia. das Letras, 2013.

CARDOSO, Fernando Henrique; FALETTO, Enzo. Dependency and development in Latin America. Berkeley. California: University of California Press, 1979.

CASANOVA, José. Public religions in the modern world. Chicago: The University of Chicago Press, 1994.

CHAKRABARTY, Dipesh. Provincializing Europe: postcolonial thought and historical difference. Princeton: Princeton University Press, 2000.

CHATTERJEE, Partha. La nación en tiempo heterogéneo. Buenos Aires: Siglo Veintiuno, 2008.

CHERNILO, Daniel. The critique of methodological nationalism: theory and history. Thesis Eleven, v. 106, n. 1, p.98-117, 2011.

COSTA, Sérgio. Teoria por adição. In: Carlos Benedito Martins; Heloísa Helena Martins (orgs.). Horizontes das ciências sociais no Brasil: Sociologia. São Paulo: Anpocs, 2010, p. 25-51.

COSTA PINTO, Luiz de Aguiar. Sociologia e desenvolvimento: temas e problemas de nosso tempo. Rio de Janeiro: Civilização Brasileira, 1973.

COSTA PINTO, Luiz de Aguiar. Desenvolvimento econômico e transição social. Rio de Janeiro: Civilização Brasileira, 1978.

CRUZ COSTA, João. A history of ideas in Brazil: the development of philosophy in Brazil and the evolution of national history. Berkeley: University of California Press, 1964.

CUNHA, Euclides. Os sertões: campanha de Canudos. Rio de Janeiro: Francisco Alves, 1981.

DÉPELTEAU, François. What is the direction of the "relational turn"? In: Christopher Powell; François Dépelteau (orgs.). Conceptualizing relational sociology: ontological and theoretical issues. New York: Palgrave Macmillan, 2013. p. 163-185.

DOMINGUES, José. Do Ocidente à Modernidade: intelectuais e mudança social. Rio de Janeiro: Civilização Brasileira, 2003.

DONATI, Pierpaolo. Relational sociology and the globalized society. In: François Dépelteau;Christopher Powell (orgs.). Applying relational sociology: relations, networks, and society. New York: Palgrave Macmillan, 2013. p. 1-24.

DURKHEIM, Émile. The rules of sociological method. New York: The Free Press, 1982.

DUSSEL, Enrique. Europa, modernidade e eurocentrismo. In: Edgardo Lander (org.). A colonialidade do saber: eurocentrismo e ciências sociais. Buenos Aires: Clacso, 2005. p. 55-70. 
ECKERSLEY, Robyn. Environmentalism and political theory: toward an ecocentric approach. Albany: State University of New York Press, 1992.

EISENSTADT, Shmuel Multiple modernities. Daedalus, v. 129, n. 1, p. 1-29, 2000.

EISENSTADT, Shmuel. Modernity and modernization. Sociopedia.isa, International Sociological Association, p.1-15, 2010 <www.sagepub.net/isa/resources/pdf/ Modernity.pdf> (24 Oct. 2017).

ELIAS, Norbert. Universal features of human society. In: Norbert Elias. What is sociology? London: Hutchinson \& Co (Publishers) Ltd, 1978a. p. 104-133.

ELIAS, Norbert. The problem of the "inevitability" of social development. In: Norbert Elias. What is sociology? London: Hutchinson \& Co. Ltd., 1978b. p. 158-174.

EMYRBAER, Mustafa. Manifesto for a relational sociology. American Journal of Sociology, v. 103, n. 2, p. 281-317, $1997<10.1086 / 231209>$.

ESCOBAR, Arturo. O lugar da natureza e a natureza do lugar: globalização ou pósdesenvolvimento? In: Edgardo Lander (org.). A colonialidade do saber: eurocentrismo e ciências sociais. Buenos Aires: Clacso, 2005. p. 133-168.

FAORO, Raymundo. Os donos do poder: formação do patronato político brasileiro. São Paulo: Globo, 2001.

FERNANDES, Florestan. A Revolução Burguesa no Brasil: ensaio de interpretação sociológica. Rio de Janeiro: Zahar, 2006.

FERNANDES, Florestan. Sociedade de classes e subdesenvolvimento. Rio de Janeiro: Zahar, 2008a.

FERNANDES, Florestan. A integração do negro na sociedade de classes. São Paulo: Editora Globo, 2008b.

FRANCO, Maria Sylvia de Carvalho. As ideias estão no lugar. Cadernos de Debate, n. 1, p. 61-64, 1976.

FREYRE, Gilberto. Manifesto regionalista. Maceió: Ed. Ufal, 1976.

FREYRE, Gilberto. Sobrados e mucambos. Rio de Janeiro: Record, 1996.

FREYRE, Gilberto. Casa-grande \& senzala: introdução à história da sociedade patriarcal no Brasil. Rio de Janeiro: Record, 2000a.

FREYRE, Gilberto. Novo mundo nos trópicos. Rio de Janeiro: Topbooks, 2000b

FREYRE, Gilberto. Tempo morto e outros tempos. São Paulo: Global, 2006.

FURTADO, Celso. Raízes do subdesenvolvimento. Rio de Janeiro: Civilização Brasileira, 2003.

FURTADO, Celso. Formação econômica do Brasil. São Paulo: Cia. das Letras, 2009. GÖLE, Nilüfer. Snapshots of Islamic modernities. Daedalus, v. 129, n. 1, p.91-117, 2000.

GUMBRECHT, Hans Ulrich. Nosso amplo presente: o tempo e a cultura contemporânea. São Paulo: Editora da Unesp, 2015.

HALL, Stuart. A identidade cultural na pós-modernidade. Rio de Janeiro: DP\&A, 2006. 
HOLLANDA, Sérgio Buarque de. Raízes do Brasil. Rio de Janeiro: José Olympio, 1936.

HUNTINGTON, Samuel. A ordem política nas sociedades em mudança. Rio de Janeiro: Forense-Universitária, 1975.

IANNI, Octavio. O colapso do populismo no Brasil. Rio de Janeiro: Civilização Brasileira, 1978.

LAGE, Victor. Interpretations of Brazil, contemporary (de)formations. Rio de Janeiro: PUC-Rio (Tese de doutorado), 2016.

LEAL, Victor Nunes. Coronelismo, enxada e voto: o município e o regime representativo no Brasil. São Paulo: Companhia das Letras, 2012.

LIEDKE, Enno. A sociologia no Brasil: história, teorias e desafios. Sociologias, v. 7 , n. 14, p. 376-437, 2005.

LIMA, Nísia. Um sertão chamado Brasil. São Paulo: Hucitec Editora, 2013.

LYNCH, Christian. Por que pensamento e não teoria? A imaginação político-social brasileira e o fantasma da condição periférica (1880-1970). Dados - Revista de Ciências Sociais, v. 56, n. 4, p. 727-766, 2013.

MAIA, João. Pensamento brasileiro e teoria social: notas para uma agenda de pesquisa. Revista Brasileira de Ciências Sociais, v. 24, n. 71, p. 155-168, $2009<10.1590 /$ S010269092009000300011>.

MAIA, João. Ao sul da teoria: a atualidade teórica do pensamento social brasileiro. Sociedade e Estado, v. 26, n. 2, p. 71-94, $2011<10.1590 /$ S0102-69922011000200005>.

MANN, Michael. Ruling class strategies and citizenship. In: Martin Blumer; Anthony Rees (orgs.). Citizenship today: the contemporary relevance of T. H. Marshall. Londres: UCL Press, 1996. p. 125-144.

MARX, Karl. Capital. v. 1. London: Penguin Books, 1990.

MIGNOLO, Walter. Local histories and global designs: coloniality, subaltern knowledges, and border thinking. Princeton: Princeton University Press, 2000.

MONTERESCU, Daniel. Spatial relationality and the fallacies of methodological nationalism: theorizing urban space and binational sociality in Jewish-Arab "mixed towns". In: François Dépelteau; Christopher Powell. (orgs). Applying relational sociology: relations, networks, and society. New York: Palgrave Macmillan, 2013. p. 25-50.

NABUCO, Joaquim. O Abolicionismo. Rio de Janeiro: Nova Fronteira/São Paulo: Publifolha, 2000.

PARSONS, Talcott. The structure of social action. Volume 1: Marshall, Pareto, Durkheim. New York: The Free Press, 1968.

PARSONS, Talcott. The system of modern societies. Englewood Cliffs: Prentice-Hall Inc, 1971.

POWELL, Christopher; DÉPELTEAU, François. Introduction. In: Christopher Powell; François Dépelteau (orgs.). Conceptualizing relational sociology: ontological and theoretical issues. New York: Palgrave Macmillan, 2013. p. 1-12. 
PRADO Jr., Caio. Formação do Brasil Contemporâneo: colônia. São Paulo: Cia. das Letras, 2011.

PRADO, Paulo. Retrato do Brasil: ensaio sobre a tristeza brasileira. São Paulo: Companhia das Letras, 2012.

PRANDINI, Riccardo. Relational sociology: a well-defined sociological paradigm or a challeging "relational turn" in sociology? International Review of Sociology, v. 25, n. 1, p. 1-14, $2015<10.1080 / 03906701.2014 .997969>$.

RAMOS,Alberto Guerreiro. A Redução Sociológica. Rio de Janeiro: Editora UFRJ, 1996.

RIBEIRO, Adelia Miglievich. Darcy Ribeiro e o pensamento crítico latino-americano: diálogos com a epistemologia póscolonial. Sinais - Revista Eletrônica - Ciências Sociais, n. 9, v. 1, p. 12-31, 2011.

RICUPERO, Bernardo. O lugar das ideias: Roberto Schwarz e seus críticos. Sociologia \& Antropologia, v. 3, n. 6, p. 526-556, 2013.

ROMERO, Silvio. História da literatura brasileira. Tomo I. Rio de Janeiro: Livraria José Olympio, 1949.

ROSTOW, Walt Whitman. As etapas do desenvolvimento econômico (um manifesto não-comunista). Rio de Janeiro: Zahar, 1978.

SCHMIDT, Volker. Conceptualizing global modernity: a tentative sketch. Singapore: National University of Singapore, 2012.

SCHWARCZ, Lilia. O espetáculo das raças: cientistas, instituições e questão racial no Brasil - 1870-1930. São Paulo: Cia. das Letras, 1993.

SCHWARZ, Roberto. As idéias fora de lugar. In: Roberto Schwarz (org.). Cultura e Política. São Paulo: Paz e Terra, 2009a. p.59-83.

SOUSA SANTOS, Boaventura de. Para além do pensamento abissal: das linhas globais a uma ecologia de saberes. In: Boaventura de Sousa Santos e Maria Paula Meneses (org.). Epistemologias do Sul. Coimbra: Almedina, 2009.

SUBRAHMANYAM, Sanjay. Connected histories: notes towards a reconfiguration of early modern Eurasia. Modern Asian Studies, v. 31, n. 3, p. 735-762, $1997<10.1017$ / S0026749X00017133>.

TAVOLARO, Sergio B. F. Existe uma modernidade brasileira? Reflexões em torno de um dilema sociológico brasileiro. Revista Brasileira de Ciências Sociais, v. 20, n. 59, p. 1-22, 2005.

TAVOLARO, Sergio B. F. Gilberto Freyre e nossa "Modernidade Tropical": entre a originalidade e o desvio. Sociologias, v. 15, n. 33, p. 282-317, $2013<10.1590 /$ S151745222013000200010>.

TAVOLARO, Sergio B. F. A tese da singularidade brasileira revisitada: desafios teóricos contemporâneos. Dados: Revista de Ciências Sociais, v. 57, n. 3, p. 633-673, 2014.

TAVOLARO, Sergio B. F. Imagens de uma outra modernidade: Gilberto Freyre e o espaço-tempo latino-americano. Política \& Sociedade, v. 15, n. 34, p. 196-231, 2016 $<10.5007 / 2175-7984.2016 v 15 n 34 p 196>$. 
THERBORN, Göran. Entangled modernities. European Journal of Social Theory, v. 6, n. 3, p. 293-305, $2003<10.1177 / 13684310030063002>$.

TORRES, Alberto. A organização nacional. Brasília: Editora UnB, 1982.

TURNER, Bryan. Outline of a theory of citizenship. Sociology, v. 24, n. 2, p. 189-217, $1990<10.1177 / 0038038590024002002>$.

VENTURA, Roberto. Estilo tropical: história cultural e polêmicas literárias no Brasil, 1870-1914. São Paulo: Companhia das Letras, 1991.

VIANNA, Oliveira. Evolução do Povo Brasileiro. Rio de Janeiro: José Olympio Editora, 1956.

VIANNA. Oliveira. Populações meridionais do Brasil. v. 1. Niterói: Ed. da UFF, 1987.

VIANNA, Luiz W. A institucionalização das ciências sociais e a reforma social: do pensamento social à agenda americana de pesquisa In: Luiz W. Vianna. A revolução passiva: iberismo e americanismo no Brasil. Rio de Janeiro: Renavan, 2004.

WEBER, Max. The protestant ethic and the spirit of capitalism. Los Angeles: Roxbury Publishing Company, 2002.

WIMMER, Andreas; SCHILLER, Nina. Methodological nationalism and beyond: nation-state building, migration and the social sciences. Global Networks, v. 2, n. 4, p. 301-334, $2002<10.1111 / 1471-0374.00043>$.

WITTROCK, Björn. Modernity: one, none or many? European origins and modernity as a global condition. Daedalus, v. 129, n. 1, p.31-60, 2000.

Recebido em: 8 fev. 2017

Aprovado em: 6 set. 2017

Autor correspondente:

Sergio Barreira de Faria Tavolaro

Departamento de Sociologia - Prédio do ICS/UnB

Campus Universitário Darcy Ribeiro - Asa Norte

70910-900 Brasília, DF, Brasil 